\section{Utilization of Out- and Inpatient Health Services by Obese Adults: a Population-Based Study in the Augsburg Region, Germany}

\author{
Inanspruchnahme ambulanter und stationärer Gesundheitsversorgung durch \\ adipöse Erwachsene: eine bevölkerungsbasierte Studie in der Region Augsburg
}

T. von Lengerke ${ }^{1,2}$

M. Happich ${ }^{1}$

P. Reitmeir ${ }^{1}$

J. John ${ }^{1}$

for the KORA Study Group

\section{Zusammenfassung}

Ziel der Studie ist der Vergleich der Inanspruchnahme ambulanter und stationärer Gesundheitsversorgung durch adipöse und normalgewichtige Erwachsene. In einer Teilstichprobe des KORA-Survey S4 1999/2001 in der Region Augsburg ( $\mathrm{n}=947$, Alter: 25 - 74 Jahre) wurde die Anzahl von Allgemeinarztbesuchen und Tagen stationären Aufenthaltes im Krankenhaus über einen Zeitraum von einem halben Jahr in drei computergestützten Telefoninterviews durch Selbstberichte erfasst. Basierend auf dem anthropometrisch bestimmten Body-Mass-Index (BMI) wurden Teilnehmer mit Normalgewicht $(18,5 \leq \mathrm{BMI}<25)$, Präadipositas $(25 \leq \mathrm{BMI}<30)$, Adipositas Klasse $1(30 \leq \mathrm{BMI}<35)$ und Adipositas Klassen 2-3 (BMI $\geq 35$ ) (WHO-Klassifikation) mittels logistischer, negativ-binomialer („zero-truncated“) und multinomialer Modelle verglichen, um die Assoziationen der Adipositas mit Inanspruchnahme und ihrer Frequenz sowie starker Inanspruchnahme zu bestimmen. In allen Modellen wurde für Geschlecht, Alter, Sozialschicht, Krankenkasse und Wohnort adjustiert. Teilnehmer mit Adipositas Klasse 1 hatten mit höherer Wahrscheinlichkeit als Normalgewichtige mindestens einmal einen Allgemeinarzt besucht $(\mathrm{OR}=1,84, \mathrm{p}<0,01)$, während Adipositas der Klassen $2-3$ mit häufigerer (IRR = 1,63, $\mathrm{p}<0,05)$ und starker Inanspruchnahme $(\mathrm{OR}=3,57, \mathrm{p}<0,05)$ assoziiert war. Im stationären Bereich (Krankenhaustage) berichteten nur die extrem Adipösen (also Klassen 2-3) signifikant mehr Inanspruchnahme als Normalgewichtige (bei $\geq 1$ Tag Aufenthalt: IRR $=3,24, p<$ $0,05$; starke Inanspruchnahme: $\mathrm{OR}=5,40, \mathrm{p}<0,01)$. Geschlecht

\section{Abstract}

The aim of this study is to compare out- and inpatient health services utilization by obese and normal weight adults. In a subsample of the KORA-Survey S4 1999/2001 in the Augsburg region, Germany ( $n=947$, age: $25-74$ years), number of visits to general practitioners (GP) and inpatient hospital days were selfreported in three computer-aided telephone interviews (CATI) over half a year. Body mass index, based on measured body height and weight, was used to define obesity according to WHO classification. Participants, stratified in normal weight $(18.5 \leq \mathrm{BMI}<25)$, preobese $(25 \leq \mathrm{BMI}<30)$, obese class 1 $(30 \leq \mathrm{BMI}<35)$ and obese classes $2-3(\mathrm{BMI} \geq 35)$, were compared via logistic, zero-truncated negative binomial, and multinomial models to elucidate obesity's associations with utilization at all, its frequency, and high utilization. Sex, age, social class, health insurance, and place of residence were adjusted for in all models. Respondents in obesity class 1 were more prone to report at least one visit to a GP than those normal weight $(\mathrm{OR}=1.84, \mathrm{p}<0.01)$, while obesity classes $2-3$ were associated with frequent (IRR $=1.63, \mathrm{p}<0.05$ ) and high utilization $(\mathrm{OR}=3.57, \mathrm{p}<0.05)$. Regarding days in hospital, only the extremely obese (i. e. classes $2-3$ ) reported significantly more utilization than those normal weight (days if hospitalized at all: IRR = 3.24, p < 0.05; high utilization: $O R=5.4, p<0.01$ ). Sex did not play a significant role in any model. Older respondents reported more utilization in terms of GP-visits, while only tending to do so regarding inpatient utilization. Both those with statu-

note

The KORA study group consists of H.-E. Wichmann (speaker), H. Löwel, C. Meisinger, T. Illig, R. Holle, J. John, and co-workers who are responsible for the design and conduct of the KORA studies.

affiliation

${ }^{1}$ GSF-National Research Center for Environment and Health, Institute of Health Economics and Health Care Management, Neuherberg, Germany

${ }^{2}$ Hannover Medical School, Medical Psychology, Hannover, Germany

correspondence

Dr. Thomas von Lengerke · Hannover Medical School, Medical Psychology, OE 5430 - Carl-Neuberg-Str. 1 . 30625 Hannover·Germany ·E-mail: lengerke.thomas@mh-hannover.de

bibliography

Gesundheitswesen 2005; 67 Sonderheft 1: S150-S157 @ Georg Thieme Verlag KG Stuttgart • New York DOI $10.1055 / \mathrm{s}-2005-858231$

ISSN 0949-7013 
spielte in keinem Modell eine signifikante Rolle. Ältere Teilnehmer berichteten über mehr Inanspruchnahme im Hinblick auf Allgemeinarztbesuche, während dies im stationären Bereich nur tendenziell der Fall war. Sowohl gesetzlich (vs. privat) Versicherte als auch Einwohner ländlicher (vs. städtischer) Gebiete hatten höhere Odds, überhaupt einen Allgemeinarzt aufgesucht zu haben. Die Ergebnisse sprechen für eine höhere Inanspruchnahme ambulanter und stationärer Gesundheitsversorgung durch Erwachsene vor allem mit extremer Adipositas und unterstreichen, dass die Unterscheidung der Adipositas Klassen 2 - 3 vs. 1 für die Versorgungsforschung von besonderer Bedeutung ist.

\section{Schlïsselwörter}

Adipositas • Inanspruchnahme ambulanter und stationärer Gesundheitsversorgung · bevölkerungsbezogene Gesundheitsforschung tory (vs. private) health insurance and rural (vs. urban) place of residence had higher odds to visit a GP at all. Results point to an excess utilization of out- and inpatient health services by especially extremely obese adults, and underline the need to contrast obesity classes $2-3$ vs. 1 in health services utilization research.

\section{Key words}

Obesity · utilization of out- and inpatient health services · population health research

\section{Introduction}

Obesity has been shown to be associated with elevated levels of health services utilization[1-9]. However, to the knowledge of the present authors there has been but one population-representative study of adults since 1990 in Germany that has assessed the impact of overweight on utilization $[10,11]$. In other words, there seems to be no non-clinical research other than that study which has examined associations of obesity and utilization among adults while adjusting for predisposing and enabling factors known to be relevant to health care utilization [12-15]. In that study $[10,11]$, which analyzed data of the German Federal Health Survey 1998 [16], obesity was positively associated with number of visits to general practitioners (GP), but neither with number of visits to any physician nor internal specialists, nor the number of kinds of specialists visited.

However, a number of features of that study - which besides is seminal for German health services research - merit further investigation when looking at obesity as a raison d'être for utilization. First, body mass - as defined by the body mass index (BMI, i. e. weight in $\mathrm{kg} /[\text { height in } \mathrm{m}]^{2}$ ) - was dichotomized so that the obese (BMI $\geq 30$ ) were contrasted to those non-obese. As earlier analyses have shown, however, adults in obesity class 2 or 3 ( $35 \leq \mathrm{BMI}<40$ or $\mathrm{BMI} \geq 40$ ) represent a population different from those in class 1 (i.e. $30 \leq \mathrm{BMI}<35$ ), for instance regarding physical health-related quality of life [17].

Second, Thode et al. deliberately focused on the utilization of outpatient services, arguing that theoretically - due to the general regulations of the German health care system - many of the factors they scrutinized (above all predisposing and enabling) should not substantially influence utilization of inpatient services. However, as obesity can be regarded to be a proxy to numerous, especially chronic diseases, it does seem appropriate to throw a glance at inpatient care of obese adults in this context, and compare it to that of their normal weight counterparts.

Third, Thode et al. deliberately circumvented issues of high utilization, presumably doing so more for reasons of time and space (specifically, i. e., given the normative issues they rightfully note to be involved here) than for reasons of irrelevance. However, especially extreme obesity may in fact be a major factor with regard to extraordinarily high levels of utilization. Thus, an explorative look at the association of obesity and high utilization may be no less than justifiable.

In sum, the present study for Germany aims to answer the following research questions:

1. Do adults in different classes of obesity utilize outpatient health services more, and/or more frequently, than those in normal weight range?

2. Do adults in different classes of obesity utilize inpatient health services more, and/or for longer periods of time (i.e. more inpatient days), than those in normal weight range?

3. Is (especially extreme) obesity associated with high utilization of out- and inpatient health services?

\section{Methods}

\section{Study population and sampling}

The KORA Survey S4 1999/2000 is a cross-sectional, populationrepresentative health survey of the resident population aged 25 to 74 in the Augsburg region (i. e. Augsburg city, plus the two adjacent administrative districts). A sample of $n=6.640$ individuals were invited to participate from Augsburg and a random sample of 16 out of 70 communities in the two districts. In sampling, within each of the 17 communities a random sample within each of 10 equal strata by sex and age was drawn from the registration office.

Of the $n=4.261$ participating in this main survey (response rate: $67 \%$ ), a random sample of $n=1.186$ with 30 nearly balanced strata by sex, age and BMI (BMI < 25, $25 \leq \mathrm{BMI}<30$, BMI $\geq 30$ ) was drawn for a three-wave computer-aided telephone interview (CATI) follow-up after two, four, and six months. In all, $\mathrm{n}=947$ participated in all waves (response rate: $80 \%$ ). In all, fieldwork lasted from October 1999 to August 2001, and on average ranged over seven and a half months for any participant. 
Of the $\mathrm{n}=947$ participants, five with a BMI $<18.5 \mathrm{~kg} / \mathrm{m}^{2}$ were excluded for reasons of cell count and probable underweightspecific health problems. Table 1 shows the resulting analysis sample $(\mathrm{n}=942$ ) by cross-tabulating BMI categories with all potential confounders considered in the analyses. For analysis, the following stratification is used according to WHO definitions [ 18 , 19] (BMI in $\mathrm{kg} / \mathrm{m}^{2}$ ): normal weight $18.5 \leq \mathrm{BMI}<25$, preobese $25 \leq \mathrm{BMI}<30$, obesity class $130 \leq \mathrm{BMI}<35$; and obesity classes $2-3 \mathrm{BMI} \geq 35$.

While sex, age and place of residence are basically equally distributed merely due to the fact that they served as stratification dimensions in sampling (besides BMI), the most conspicuous difference in this context pertains to the fact that among those in obesity classes $2-3$, women with $66.7 \%$ represent a comparably strong majority. Furthermore, while no great differences relate to the distribution of statutory vs. private health insurance within body mass categories, respondents from the lower socio-economic echelon are more strongly represented in obese (class 1 : $30.2 \%$, classes $2-3: 30.9 \%$ ) than in nonobese groups (normal weight: $15.8 \%$, preobese: $18.2 \%)$.

\section{Measures}

The indicators of health services utilization used in the present study were assessed via self-report in each of the CATI followups. As an indicator of out-patient utilization, the numbers of visits to GP in the three eight weeks-periods preceding the follow-ups were summed up as an estimator of the number of visits within the study period. The items read as follows: "How often did you visit a physician in the last eight weeks?", and - for each of the visits - "Which medical field did that physician belong to?". Likewise, inpatient utilization was assessed by adding up the numbers of days spent in hospital. Here, the following items were used: "Have you stayed in hospital overnight (i. e. inpatient) during the last eight weeks?", and "In sum, how many days have you spent in hospital for inpatient care during the last eight weeks?".

\section{Obesity}

Body weight and height were assessed within the anthropometric examination in the main survey. Calibration of measuring instruments was ensured by weekly or daily inspections using standard weights or resistors, as appropriate. Body mass was indexed for each participant as ([weight in $\mathrm{kg}] /[\text { height in } \mathrm{m}]^{2}$ ). Overweight groups were defined following WHO classifications (see above) $[18,19]$.

\section{Predisposing and enabling factors}

Sex, age and place of residence were known in advance for each participant due to the sampling procedure. Social class was indicated by the revised index by Helmert which is based on education, occupational status, and income (for details, see [20]), the assessment of which followed national recommendations [21]. Kind of sickness fund was assessed by asking participants whether their fund was statutory (German 'GKV') or private ('PKV').

\section{Statistical analysis}

Following a descriptive analysis, two-part models [22] were performed for each of the two utilization parameters. In each model, the first-step equation models the probability that respondents reported any relevant utilization at all, employing a logistic model (procedure LOGISTIC in STATA/SE 8.1 for Windows). In contrast, the second-step equation models the frequency of utilization among users, employing a zero-truncated negative binomial model (procedure trnbin0 in STATA/SE 8.1 for Windows). This approach is appropriate here because counts are examined with no possibility of having zero values; as coefficients, incident rate ratios (IRR) are reported describing changes in outcome associated with a one unit increase in regressors.

Table 1 Distributions of potential confounders by groups of body mass index (BMI) ${ }^{1}(n=942$, KORA Survey S4 1999/2001, Sub-study "Costs of illness related to obesity")

\begin{tabular}{|c|c|c|c|c|c|}
\hline & $\begin{array}{l}\text { normal weight } \\
(n=304)\end{array}$ & $\begin{array}{l}\text { preobese } \\
(n=324)\end{array}$ & $\begin{array}{l}\text { obese class } 1 \\
(n=233)\end{array}$ & $\begin{array}{l}\text { obese classes } 2-3 \\
(n=81)\end{array}$ & TOTAL \\
\hline women & $163(53.6 \%)$ & $164(50.6 \%)$ & $111(47.6 \%)$ & $54(66.7 \%)$ & $492(52.2 \%)$ \\
\hline $25-35$ years of age & 65 (21.4\%) & $59(18.2 \%)$ & $39(16.7 \%)$ & $15(18.5 \%)$ & $178(18.9 \%)$ \\
\hline $35-45$ years of age & 59 (19.4\%) & $63(19.4 \%)$ & $51(21.9 \%)$ & $14(17.3 \%)$ & 187 (19.9\%) \\
\hline $45-55$ years of age & $56(18.4 \%)$ & $68(21.0 \%)$ & $44(18.9 \%)$ & $25(30.9 \%)$ & $193(20.5 \%)$ \\
\hline $65-75$ years of age & $63(20.7 \%)$ & $65(20.1 \%)$ & $49(21.0 \%)$ & $13(16.0 \%)$ & $190(20.2 \%)$ \\
\hline upper social class & 60 (19.7\%) & $57(17.6 \%)$ & $28(12.1 \%)$ & $10(12.3 \%)$ & $155(16.5 \%)$ \\
\hline middle social class & $196(64.5 \%)$ & $208(64.2 \%)$ & $134(57.8 \%)$ & $46(56.8 \%)$ & $584(62.1 \%)$ \\
\hline lower social class & $48(15.8 \%)$ & $59(18.2 \%)$ & $70(30.2 \%)$ & $25(30.9 \%)$ & $202(21.5 \%)$ \\
\hline private health insurance & $52(17.2 \%)$ & $45(14.2 \%)$ & $29(12.6 \%)$ & $9(11.3 \%)$ & 135 (14.5\%) \\
\hline statutory health insurance & $251(82.8 \%)$ & $271(85.8 \%)$ & $202(87.4 \%)$ & $71(88.8 \%)$ & 795 (85.5\%) \\
\hline
\end{tabular}

Notes: Sex and age were stratification dimensions in sampling besides BMI for the present analysis sample (see text), and sex, age and place of residence in the main survey from which the present sample was drawn; thus, cross-tabulations with BMI may in no way be viewed as reflecting the situation in the population. ${ }^{1}$ Definition of BMl groups see text. 
Besides, to elucidate the conditions of high utilization, multinomial regression models were employed in which on the side of each regressand three levels were distinguished: no utilization at all (= reference group), some utilization, and high utilization (procedure NOMREG in SPSS 12.0.1 for Windows). The latter was defined as the upper $5 \%$ of the distribution in case of GP visits, and as the upper $2.5 \%$ in case of days spent in hospital. For reasons of relevance to the research questions put forward above, and for ease of presentation, only statistics for the 'high vs. no'contrast will be reported in the Results-section.

In each of the models, the four BMI-groups as described before defined the focal regressor, using 'normal weight' as the reference group. As covariates, sex, age, lower and middle vs. upper social class, statutory vs. private health insurance, and rural vs. urban place of residence (i. e. living in one of the two adjacent districts vs. Augsburg city) were entered into each model.

\section{Results}

Table 2 presents the observed distributions of the number of visits to GP and days spent in hospital by the predisposing and enabling factors selected for the analysis, and by BMI-groups. Proportions of respondents who had visited a GP at all were virtually the same in women and men, but higher among the elderly and those from the lower social class. While more than half of those whose sickness cover was statutory had visited a GP at all, only about a third of the privately insured had done so. Furthermore, more people living in a rural than an urban area had attended a GP. As for obesity, contrary to expectation not those in classes 2 but those in obesity class 1 (64.2\%).

Regarding the frequency of visits among those who had reported at least one, patterns are not entirely similar. While again no substantial difference is observed between sexes, and while utilization again increases with age, no clear pattern is observable across social classes. Also, differences both between the statutory vs. privately insured and rural vs. urban dwellers seem to be of lesser magnitude. That is, those insured in the "GKV" and those living in more rural areas tend to have any GP contact with a higher probability than their private and urban counterparts, respectively. Concurrently, those who did go obviously did not do so more frequently. Finally, there is a clear contrast with regard to obesity: while those in classes 2 or 3 were only second place in reporting any GP contact (57.5\%), those who did go did so more often than those in obesity class 1 (mean 4.21, vs. 3.24 in the latter group). Also, looking at high utilization the obese in class 2-3 have the second highest proportion of people with at least eight GP visits over half a year (10.0\%), only outdone by those respondents aged $65-74$ years $(10.6 \%)$.

Hospital utilization as expected varies on a quite lower level than GP visits in terms of the proportion of respondents reporting any utilization (for the total sample: 5.4\%). Distributions along the factors kind of sickness fund (more statutory) and place of residence (more rural) are roughly comparable to those regarding GP visits. For other factors, partially different patterns emerge. For instance, while only small differences pertain to being hospitalized at all across social classes, those from the lower echelon had clearly been inpatient longer than those from middle and

Table 2 Visits to general practitioners (GP) and inpatient days over half a year, by sex, age, social class, health insurance, place of residence, and obesity (four BMI-groups ${ }^{1}$, KORA-Survey S4 1999/2001, Sub-study “Costs of illness related to obesity”)

\begin{tabular}{|c|c|c|c|c|c|c|c|c|c|c|}
\hline & \multicolumn{5}{|c|}{ number of visits to general practitioners } & \multicolumn{5}{|c|}{ number of days in hospital (inpatient) } \\
\hline & \multirow{2}{*}{$\% \geq 1$} & \multicolumn{3}{|c|}{ within $\geq 1$} & \multirow{2}{*}{$\begin{array}{l}\% \geq 8 \\
\text { (upper } \\
5 \text { pctiles) }\end{array}$} & \multirow{2}{*}{$\% \geq 1$} & \multicolumn{3}{|c|}{ within $\geq 1$} & \multirow{2}{*}{$\begin{array}{l}\% \geq 7 \\
\text { (upper } \\
2.5 \text { pctiles) }\end{array}$} \\
\hline & & mean & median & $\min -\max$ & & & mean & median & $\min -\max$ & \\
\hline women & $53.9 \%$ & 3.32 & 2.0 & $1-18$ & $4.9 \%$ & $4.9 \%$ & 10.41 & 6.5 & $1-49$ & $2.4 \%$ \\
\hline men & $53.2 \%$ & 3.27 & 2.0 & $1-20$ & $5.1 \%$ & $6.0 \%$ & 12.41 & 7.0 & $1-41$ & $3.3 \%$ \\
\hline $25-34$ years of age & $43.3 \%$ & 2.65 & 2.0 & $1-18$ & $1.1 \%$ & $5.6 \%$ & 5.70 & 4.5 & $1-15$ & $1.7 \%$ \\
\hline $35-44$ years of age & $45.9 \%$ & 2.52 & 2.0 & $1-09$ & $2.7 \%$ & $5.9 \%$ & 8.09 & 6.0 & $2-30$ & $2.7 \%$ \\
\hline $45-54$ years of age & $46.1 \%$ & 3.20 & 2.0 & $1-17$ & $5.2 \%$ & $3.6 \%$ & 13.42 & 9.0 & $1-40$ & $2.6 \%$ \\
\hline $55-64$ years of age & $63.2 \%$ & 3.60 & 3.0 & $1-20$ & $5.2 \%$ & $5.7 \%$ & 16.36 & 13.0 & $2-49$ & $3.1 \%$ \\
\hline $65-74$ years of age & $68.6 \%$ & 3.97 & 3.0 & $1-17$ & $10.6 \%$ & $6.3 \%$ & 13.75 & 9.0 & $1-41$ & $4.2 \%$ \\
\hline upper social class & $43.2 \%$ & 3.76 & 3.0 & $1-18$ & $5.1 \%$ & $5.2 \%$ & 8.25 & 6.5 & $1-20$ & $2.6 \%$ \\
\hline middle social class & $52.5 \%$ & 3.11 & 2.0 & $1-20$ & $4.6 \%$ & $5.6 \%$ & 10.69 & 7.0 & $1-49$ & $2.9 \%$ \\
\hline lower social class & $65.0 \%$ & 3.50 & 3.0 & $1-14$ & $6.0 \%$ & $5.0 \%$ & 16.60 & 14.5 & $1-40$ & $3.0 \%$ \\
\hline private health insurance & $34.1 \%$ & 3.28 & 2.0 & $1-17$ & $3.0 \%$ & $4.4 \%$ & 11.00 & 6.0 & $2-35$ & $2.2 \%$ \\
\hline statutory health insurance & $56.7 \%$ & 3.31 & 2.0 & $1-20$ & $5.4 \%$ & $5.7 \%$ & 11.53 & 7.0 & $1-49$ & $3.0 \%$ \\
\hline urban residence & $47.0 \%$ & 3.16 & 2.0 & $1-17$ & $4.6 \%$ & $5.0 \%$ & 12.42 & 9.0 & $1-49$ & $3.3 \%$ \\
\hline rural residence & $58.8 \%$ & 3.38 & 2.0 & $1-20$ & $5.4 \%$ & $5.7 \%$ & 10.80 & 5.5 & $1-41$ & $2.5 \%$ \\
\hline normal weight & $48.0 \%$ & 2.92 & 2.0 & $1-18$ & $3.6 \%$ & $4.9 \%$ & 8.46 & 4.0 & $1-40$ & $2.0 \%$ \\
\hline preobese & $50.2 \%$ & 3.43 & 2.0 & $1-17$ & $5.9 \%$ & $4.6 \%$ & 8.93 & 6.0 & $1-41$ & $2.2 \%$ \\
\hline obese class 1 & $64.2 \%$ & 3.24 & 2.0 & $1-20$ & $3.9 \%$ & $5.6 \%$ & 12.23 & 7.0 & $1-35$ & $3.0 \%$ \\
\hline obese classes $2-3$ & $57.5 \%$ & 4.21 & 3.0 & $1-14$ & $10.0 \%$ & $9.9 \%$ & 20.62 & 17.0 & $5-49$ & $8.6 \%$ \\
\hline
\end{tabular}

Notes: unadjusted data; m: mean, med: median, min-max: minimum-maximum, pctiles: percentiles. ${ }^{1}$ Definition of BMI groups see text. 
upper classes (mean $=16.60$ days, vs. 10.9 and 8.25 , respectively) Finally, regarding obesity, results are clear-cut. First, the proportion of respondents in obesity classes $2-3$ who had been hospitalized at all is approximately twice of those in the other groups (9.9\%). Second, this group was hospitalized for extraordinarily large number of days (mean $=20.62$ days, vs. $12.23,8.93$ and 8.46 in the other BMI-groups, respectively). Lastly, high utilization (corresponding to the upper 2.5 percentiles of the distribution in the total sample) was much more prevalent again in the extremely obese compared to the other groups: $8.6 \%$ of the former spent seven or more days in hospital, while even in the other obese group (class 1 ), this proportion was only $3 \%$, and ranged down to $2.0 \%$ in the normal weight group.

In order to hedge these results against chance variations and, more importantly, confounding by other factors that may predispose to or enable utilization, inference statistical modeling was conducted for both indicators of utilization (number of visits to GP, number of days in hospital). This was accomplished by scrutinizing the probability of respondents to report any relevant utilization at all (logistic models), frequent utilization (among users: zero-truncated negative binomial models), and high utilization (multinomial models, of which only the statistics for the ‘high vs. no'-contrast are reported hereafter).

Table 3 shows the results of these models. Sex differences in utilization are negligible and statistically insignificant in case of GP visits, and stronger but again insignificant in case of days in hospital. Older respondents clearly reported more utilization in terms of GP visits, most notably by 17.77 times higher odds of eight or more GP visits in the oldest vs. the youngest group $(\mathrm{p}<0.001)$. A similar assertion holds for days in hospitals, however not reaching statistical significance other than for those aged 65-75 who report more days than the youngest group if hospitalized at all (IRR $=3.26, p<0.05)$. Results for social class strongly resemble those in the descriptive analysis reported before, but for the most part are not statistically significant. Furthermore, noteworthy contrasts pertain to any GP utilization (vs. none) in that those in statutory health insurance (vs. private) as well as rural (vs. urban) dwellers report this more often. The statutorily insured also tend to have a comparatively high chance for high GP utilization ( $\mathrm{OR}=3.09$, ns). Regarding the considerable difference between rural and urban dwellers, one explanation might be the lower density of medical specialists in the districts adjacent to Augsburg City. Finally, turning to the focal correlate of utilization scrutinized in the present study, the multivariable analyses confirm the descriptive accounts of differences between the obese and normal weight respondents. That is, while respondents in obesity class 1 differ significantly from those normal weight in their tendency to report any visit to $G P(O R=1.84, p<$ 0.01 ), among those who did go to the GP a similar assertion pertains only to those in obesity class 2 or $3(\operatorname{IRR}=1.63, \mathrm{p}<0.05)$. Also, the odds of high utilization are about 3.6 times higher in this latter group than in those in normal weight range $(\mathrm{p}<$ 0.05 ). Finally, regarding utilization of hospitals, again the obesity classes $2-3$ stand out. Not only are the odds of at least one inpatient day 2.39 times higher among these extremely obese than among the non-overweight group (ns), the former also report

Table 3 Visits to general practitioners (GP) and inpatient days over half a year, by sex, age, social class, health insurance, place of residence, and obesity (four BMI-groups ${ }^{1}$, adjusted estimates, KORA-Survey S4 1999/2001, Sub-study "Costs of illness related to obesity")

\begin{tabular}{|c|c|c|c|c|c|c|}
\hline & \multicolumn{3}{|c|}{ number of visits to general practitioners } & \multicolumn{3}{|c|}{ number of days in hospital (inpatient) } \\
\hline & $\begin{array}{l}\text { any utilization } \\
\text { vs. none }\end{array}$ & $\begin{array}{l}\text { if any: } \\
\text { how much? }\end{array}$ & $\begin{array}{l}\text { high utilization } \\
\text { vs. none }\end{array}$ & $\begin{array}{l}\text { any utilization } \\
\text { vs. none }\end{array}$ & $\begin{array}{l}\text { if any: } \\
\text { how much? }\end{array}$ & $\begin{array}{l}\text { high utilization } \\
\text { vs. none }\end{array}$ \\
\hline & OR & IRR & OR & OR & IRR & OR \\
\hline women & 1 & 1 & 1 & 1 & 1 & 1 \\
\hline men & 1.06 & 1.02 & 1.16 & 1.33 & 1.50 & 1.61 \\
\hline $35-45$ years of age & 1.12 & 0.96 & 2.59 & 1.05 & 1.50 & 1.66 \\
\hline $45-55$ years of age & 1.10 & 1.31 & 4.53 & 0.60 & 1.51 & 1.36 \\
\hline $55-65$ years of age & $2.41^{* * *}$ & $1.57^{*}$ & $7.64^{*}$ & 1.04 & 1.66 & 1.94 \\
\hline $65-75$ years of age & $3.01^{* * *}$ & $1.82^{* *}$ & $17.77^{* * *}$ & 1.15 & $3.26^{*}$ & 2.60 \\
\hline upper social class & 1 & 1 & 1 & 1 & 1 & 1 \\
\hline middle social class & 1.10 & $0.69^{*}$ & 0.81 & 1.02 & 1.53 & 1.07 \\
\hline urban place of residence & 1 & 1 & 1 & 1 & 1 & 1 \\
\hline rural place of residence & $1.67^{* * *}$ & 1.06 & 1.59 & 1.15 & 0.90 & 0.72 \\
\hline normal weight & 1 & 1 & 1 & 1 & 1 & 1 \\
\hline preobese & 1.01 & 1.20 & 1.57 & 0.95 & 0.72 & 1.09 \\
\hline obese class 1 & $1.84^{* *}$ & 1.13 & 1.49 & 1.14 & 1.72 & 1.49 \\
\hline obese class 2 or 3 & 1.42 & $1.63^{*}$ & $3.57^{*}$ & 2.39 & $3.24^{*}$ & $5.40 * *$ \\
\hline
\end{tabular}

Notes: Three models each for GP visits and inpatient days (logistic for any utilization at all, zero-truncated negative-binomial [conditional on utilization greater nil], and multinomial for high utilization); OR: odds ratio; IRR: incident rate ratio; estimates from multinomial models with reference group "no utilization" (high vs. nocontrast shown only); ${ }^{*} \mathrm{p}<0.05{ }^{* *} \mathrm{p}<0.01{ }^{* * *} \mathrm{p}<0.001 ;{ }^{1}$ Definition of BMl groups see text. 
significantly more days if hospitalized at all $(\operatorname{IRR}=3.24, \mathrm{p}<0.05)$, and most notably have 5.4 times higher odds of high utilization $(\mathrm{p}<0.01)$.

\section{Discussion}

The present study set out to analyze obesity as a correlate of two selected indicators of out- and inpatient health services utilization, based on data from a population-representative health survey in the Augsburg region, Germany (KORA Survey S4 1999/ 2001). Results can be summarized as follows. First, any visit to a GP to have happened at all was significantly more probable among those in obesity class 1 but not among those in classes $2-3$, when compared to those in normal weight range. At the same time, among those who did visit GP, those in obesity classes 2-3 did so significantly more often than their normal weight counterparts, while this assertion does not hold for respondents in obesity class 1 . Second, an inpatient stay in hospital was significantly more probable than in those normal weight only among the extremely obese (i.e. class 2 or 3 ). In contrast, regarding the number of days in hospitals among users, both obese groups spent longer periods of time in hospital than those in normal weight range. However, this failed to reach statistical significance due to the smaller base rate of participants who had been hospitalized at all. Third, regarding high utilization, in both the out- and the inpatient sector only those in obesity classes $2-3$ but not those in class 1 are significantly more likely to report "high" utilization than the normal weight group.

Thus, the research questions stated at the outset of the present analysis can be answered as follows. On one hand, obesity generally does go with a more pronounced utilization of out-and inpatient health services. On the other hand, if such differences occur, they for the most part hold only for those in obesity classes $2-3$ for all outcomes but visiting a GP at all. In other words, compared with normal weight participants, any visit to a GP is more probable among those slightly but not among those extremly obese; at the same time, a significantly higher frequency in visits to GP is found only in the extremely obese. Similar assertions hold for numbers of GP visits tantamount to high utilization, being hospitalized at least once, and being hospitalized for at least seven days over half a year (if at all). In sum, and keeping in mind that especially the difference between obesity classes $2-3$ vs. 1 in regard to any GP visit should not be over-interpreted, there seems to be a tendency for obesity to be associated with excess health services utilization only if it is extreme.

Before drawing some conclusions based on these results, some limitations of the present study have to be considered. First, utilization was assessed by self-reports, thus falling short of the "gold standard" of insurance data in the context of visits to physicians and inpatient days. However, the survey assessment strategy also holds an advantage, namely to be able to compile a lot of other information on the individual level such as psychosocial variables [17], which have been argued to be relevant to the issue of health care utilization as well [15]. Second, the response rate of $80 \%$ in a follow-up of participants of a health survey that itself had a response rate of $67 \%$ may only just be within methodical standards in survey research. Third, the representativeness of the study sample from the Augsburg region for the whole of Germany still has to be examined in future analysis (see below, Future planning). Finally, and most importantly, stratified analysis as well as tests for effect modifications was neither the focus of this study nor possible in a comprehensive way due to methodical constraints (most notably sample size). Explorative analysis of interaction terms between the BMI-factor and sex at any rate revealed that the latter did not conspicuously modify the associations between obesity and utilization. Nevertheless, the need to more deeply conduct subgroup analysis is acknowledged here, both from the view of health services epidemiology and health economics [23]. At the same time, analyses such as those in the present study still have an added value in health services research because they do shed light on excess utilization attributable to certain health states such as obesity by taking into account that utilization would have been incurred in the absence as well [24].

In sum, to our knowledge this is but the second population-representative study of adults in Germany since 1990 that has assessed excess utilization attributable to obesity. As Thode et al. $[10,11]$ for the whole of Germany, our analyses indicate for a regional population in Southern Germany that services by GP are generally utilized more by obese than normal weight adults. Most notably, those among the extremely obese who had visited a GP at all reported a higher frequency of visits. Going beyond the scope of the analysis by Thode et al., our data suggest that both inpatient and high out- and inpatient utilization is more pronounced as well, however only in those with obesity by classes $2-3$.

In a nutshell, our results point to an excess utilization of out- and inpatient health services especially by extremely obese adults. This also underlines the added value of differentiating obesity classes 1 vs. $2-3$ in health services utilization research. Of course, this may depend on the kind of utilization. Meisinger et al., for instance, in a recent study with female participants of the MONICA Augsburg Survey S3 (1994/95) [25], among other things found delayed routine cancer screening use in obese vs. normal weight women, but no excess utilization of inpatient services. In other words, for cancer screening use (Meisinger et al.'s focal outcome variable) treating those with a BMI $\geq 30$ as one homogeneous group may be entirely appropriate. In contrast, the present study demonstrates that distinguishing subgroups with different grades of obesity may be quite important, e. g. when scrutinizing inpatient utilization.

Finally, this study underscores the need to treat and prevent (especially extreme) obesity in order to appropriately manage out- and inpatient health care utilization. This is a topical objective for health policy both in light of the high and increasing prevalence of obesity (not least in the Augsburg region [26]), and considering the numerous options available for preventive policies in this context $[19,27]$.

\section{Future planning}

While this paper has focused on describing and modeling the associations of obesity with selected indicators of health services 
utilization, future plans of the GSF-Institute of Health Economics and Health Care Management in cooperation with the Hannover Medical School (Medical Psychology) within obesity research include the following:

\section{Costing the problem}

Using an adequate quantity of resource utilization, which will include a range of parameters relevant both to direct and indirect costs, it is planned to assess the health care costs attributable to obesity in the S4-sample described above. On this basis, projections are planned to the Augsburg region, and possibly other geographic and/or administrative units.

\section{Exploring longitudinal associations}

In follow-up surveys, it is planned to examine associations between duration of and changes in obesity status, and the utilization and costs of health care.

\section{Evaluating preventive interventions}

Moving beyond costs of illness studies, it is projected to explore the economic impact of policies to prevent obesity as a risk factor. In the past, such policies have proven to have only limited success, in particular among socially disadvantaged groups. Against this background, further research will pursue to identify promising approaches to promote physical activity among such groups (e. g. women with a comparably low socio-economic status), and especially their evaluability in terms of their financial and health impact.

\section{Acknowledgement}

The investigation has been supported by the GSF-National Research Center for Enviroment and Health. The authors wish to thank all present and former members of the KORA Study Group, especially Christian Janßen PhD (now at University of Cologne, Institute and Polyclinic of Occupational Medicine, Social Medicine and Public Health), Andreas Mielck PhD and Walter Satzinger PhD (both at GSF-Institute for Health Economics and Health Care Management), and Kerstin Wüstner $\mathrm{PhD}$ (now at University of Augsburg, Special Chair for Applied Psychology), for their responsibilities taken in earlier phases of the S4-subproject "Costs of illness related to obesity", PD Rolf Holle PhD for his guidance of what is feasible (and what is not), Angela Döring (GSF-Institute for Epidemiology) for sharing her expertise in obesity research, and Hannelore Nagl and Andrea Wulff (both at GSF-Institute for Health Economics and Health Care Management) for their diligent assistance in medical documentation. Last but not least, we would like to express our appreciation to Sebastian Baumeister (Ernst Moritz Arndt University of Greifswald, Institute of Epidemiology and Social Medicine, and UCLA School of Public Health, Department of Health Services) for his valuable co-operation both on substantive and statistical issues relevant to the utilization of health care.

The article relates specifically to the following contributions of this special issue of Das Gesundheitswesen: [26, 28 -35].
References

${ }^{1}$ Heithoff KA, Cuffel BJ, Kennedy S et al. The association between body mass and health care expenditures. Clin Ther 1997; 19: 811 - 820

${ }^{2}$ Berg G, Delaive K, Manfreda J et al. The use of health-care resources in obesity-hypoventilation syndrome. Chest 2001; 120: 377-383

${ }^{3}$ Bradham DD, South BR, Saunders HJ et al. Obesity-related hospitalization costs to the U.S. Navy, 1993 to 1998. Mil Med 2001; 166: 1-10

${ }^{4}$ Pronk NP, Tan AW, O'Connor P. Obesity, fitness, willingness to communicate and health care costs. Med Sci Sports Exerc 1999; 31: $1535-1343$

${ }^{5}$ Quesenberry CP Jr, Caan B, Jacobson A. Obesity, health services use, and health care costs among members of a health maintenance organization. Arch Intern Med 1998; 158: 466- 472

${ }^{6}$ Reidpath DD, Crawford D, Tilgner L et al. Relationship between body mass index and the use of healthcare services in Australia. Obes Res 2002; 10: $526-531$

${ }^{7}$ Sansone RA, Sansone LA, Wiederman MW. The relationship between obesity and medical utilization among women in a primary care setting. Int J Eat Disord 1998; 23: 161 - 167

${ }^{8}$ Sturm R. The effects of obesity, smoking, and drinking on medical problems and costs. Obesity outranks both smoking and drinking in its deleterious effects on health and health costs. Health Aff (Millwood) 2002; 21: $245-253$

9 Tucker LA, Clegg AG. Differences in health care costs and utilization among adults with selected lifestyle-related risk factors. Am J Health Promot 2002; 16: 225-233

${ }^{10}$ Thode N, Bergmann E, Kamtsiuris P et al. Einflussfaktoren auf die Inanspruchnahme des deutschen Gesundheitswesens und mögliche Steuerungsmechanismen [Schlussbericht, Vorhaben des Förderschwerpunktes "Versorgungsforschung" der DLR]. Berlin: Robert KochInstitut, 2004

11 Thode N, Bergmann E, Kamtsiuris P et al. Einflussfaktoren der ambulanten Inanspruchnahme in Deutschland. Bundesgesundheitsblatt 2005; 48: 296-306

${ }^{12}$ Andersen RM, Aday LA. Access to medical care in the U.S.: realized and potential. Med Care 1978; 16: 533-546

${ }^{13}$ Andersen RM. Revisiting the behavioral model and access to medical care: does it matter? J Health Soc Behav 1995; 36: 1 - 10

${ }^{14}$ Andersen RM, Davidson PL. Improving access to care in America: individual and contextual indicators. In: Andersen RM, Rice TH, Kominski GF (Hrsg). Changing the U.S. health care system: key issues in health services, policy, and management. San Francisco, CA: Jossey-Bass, 2001: 3-30

15 Bradley EH, McGraw SA, Curry L et al. Expanding the Andersen model: the role of psychosocial factors in long-term care use. Health Serv Res 2002; 37: 1221 - 1242

${ }^{16}$ Bellach BM. Editorial: Der Bundes-Gesundheitssurvey 1998 - Erfahrungen, Ergebnisse, Perspektiven. Gesundheitswesen 1999; 61 Spec No: S55-S56

${ }^{17}$ Lengerke Tv, John J, Janßen C. Quality of life, health locus of control, sense of coherence and social network in obese versus normal-weight participants of the KORA-Survey 2000 (Augsburg, Germany) [Abstract]. Psychol Health 2004; 19 (Suppl.): $188-189$

${ }^{18}$ Must A, Spadano J, Coakley EH et al. The disease burden associated with overweight and obesity. JAMA 1999; 282: 1523-1529

${ }^{19}$ WHO. Obesity: preventing and managing the global epidemic [Technical Report Series No. 894]. Geneva: WHO, 2000

${ }^{20}$ Mielck A. Soziale Ungleichheit und Gesundheit. Bern: Hans Huber, 2000

21 Jöckel KH, Babitsch B, Bellach BM et al. Empfehlungen der Arbeitsgruppe "Epidemiologische Methoden" in der Deutschen Arbeitsgemeinschaft Epidemiologie der Gesellschaft für Medizinische Informatik, Biometrie und Epidemiologie (GMDS) und der Deutschen Gesellschaft für Sozialmedizin und Prävention (DGSMP) zur Messung und Quantifizierung soziodemographischer Merkmale in epidemiologischen Studien. In: Ahrens W, Bellach B-M, Jöckel K-H, eds (Hrsg). Messung soziodemographischer Merkmale in der Epidemiologie (RKI-Schriften 1/98). Munich: MMV Medizin-Verlag, 1998: 7-38

22 Diehr P, Yanez D, Ash A et al. Methods for analyzing health care utilization and costs. Ann Rev Public Health 1999; 20: 125 - 144

${ }^{23}$ John J, Leidl R. Zur Bedeutung von ökonomischen Evaluationen beim Ein- und Ausschluss von Leistungen. Sozialer Fortschritt 2004; 53 : 219-228 
${ }^{24}$ Hurley SF, Bond LM, Carlin JB et al. A method for estimating baseline health care costs. J Epidemiol Community Health 1995; 49: 525-531

${ }^{25}$ Meisinger C, Heier M, Löwel $\mathrm{H}$. The relationship between body weight and health care among German women. Obes Res 2004; 12: $1473-$ 1480

${ }^{26}$ Döring A, Meisinger C, Thorand et al. Ernährungsverhalten und Übergewicht in den MONICA/KORA-Studien. Gesundheitswesen 2005; 67 S1: S51 - S57

${ }^{27}$ Lengerke Tv, John J. Letter to the Editor: On individualism, environmentalism, and the degree of complexity needed in obesity prevention: a response to Mokdad (2003). Soz Praventivmed 2004; 49: 5 - 7

${ }^{28}$ Löwel H, Döring A, Schneider A et al. The MONICA Augsburg surveys basis for prospective cohort studies. Gesundheitswesen 2005; 67 S1: $\mathrm{S} 13-\mathrm{S} 18$

${ }^{29}$ Holle R, Happich M, Löwel H et al. KORA - A research platform for population based health research. Gesundheitswesen 2005; 67 S1: S19-S25

${ }^{30}$ Wichmann HE, Gieger C, Illig T for the KORA Study Group. KORA-gen - Resource for population genetics, controls and a broad spectrum of disease phenotypes. Gesundheitswesen 2005; 67 S1: S26 -S30

${ }^{31}$ Löwel H, Meisinger C, Heier M et al. The population-based Acute Myocardial Infarction (AMI) Registry of the MONICA/KORA study region of Augsburg. Gesundheitswesen 2005; 67 S1: S31 -S37

${ }^{32}$ Mielck A, Reisig V, Rathmann W for the KORA Study Group. Health inequalities among persons with type 2 diabetes: The example of intermittent claudication. Gesundheitswesen 2005; 67 S1: S137-S143

${ }^{33}$ Eller M, Satzinger W, Holle R et al. Disease Management Programme in Deutschland: Erste Reaktionen der Diabetiker. Gesundheitswesen 2005; 67 S1: S144-S149

${ }^{34}$ Werner A, Reitmeir P, John J. Kassenwechsel und Risikostrukturausgleich in der gesetzlichen Krankenversicherung - empirische Befunde der Kooperativen Gesundheitsforschung in der Region Augsburg (KORA). Gesundheitswesen 2005; 67 S1: S158 - S166

35 Icks A, Rathmann W, Haastert B et al. Cost-effectiveness of type 2 diabetes screening: Results from recently published studies. Gesundheitswesen 2005; 67 S1: S167-S171 